\title{
COLAPSO FINANCEIRO LEVA AO CAOS SOCIAL E À INTERVENÇÃO FEDERAL NA SEGURANÇA DO RIO DE JANEIRO
}

Coluna publicada em 6.3.2018: <https://www.conjur.com.br/2018-mar-06/contas-vistacolapso-financeiro-leva-caos-social-intervencao-federal-ri>

As últimas semanas foram tomadas pela notícia da intervenção federal no estado do Rio de Janeiro. Embora tenha sido feita na área da segurança pública, ${ }^{1}$ a intervenção tem como causa remota a grave crise fiscal enfrentada pelo estado.

O Rio de Janeiro, infelizmente, tem sido um verdadeiro case para o Direito Financeiro. Inovou em junho de 2016 ao decretar o "estado de calamidade pública" em razão de sua crítica situação financeira (Crise leva as finanças públicas ao "estado de calamidade", nesta edição, p. 439-442) e, mais recentemente, tornou-se "cliente" da Lei de Recuperação Fiscal (ver Um salve pela recuperação financeira do estado do Rio de Janeiro!, nesta edição, p. 449-454), aderindo ao novo regime de recuperação fiscal por ela instituído.

A intervenção federal em um estado da federação é uma drástica medida prevista no artigo 34 da Constituição, pois importa em mitigar a autonomia desse ente federado, cabível apenas nas hipóteses excepcionais lá elencadas. Torna-se, por vezes, uma necessidade, como em "situaçóes em que a paz social ou a governabilidade do país não possam mais ser asseguradas por medidas convencionais", ${ }^{2}$ como parece ser o caso do Rio de Janeiro.

A medida está sendo usada pela primeira vez desde que promulgada a Constituição vigente, há quase 30 anos. No caso, fundou-se no inciso III, que prevê essa medida excepcional para "pôr termo a grave comprometimento da ordem pública".

1 O Interventor terá poderes sobre a Secretaria de Estado da Segurança do Estado do Rio de Janeiro, a Secretaria de Administração Penitenciária do Estado do Rio de Janeiro e do Corpo de Bombeiros Militar do Estado do Rio de Janeiro (Decreto 9.288/2018, art. 4º).

2 LEWANDOWSKI, Ricardo. Intervenção federal como necessidade. Jornal O Globo, 20 de abril de 2017. 
Foi motivada pela crescente criminalidade no Rio de Janeiro, que não tem sido combatida satisfatoriamente pela ação dos órgãos de segurança pública do próprio estado, deixando a população desprotegida, vitimada pelos criminosos e sujeita a permanente situação de insegurança.

Há hipóteses de intervenção específicas para problemas financeiros, como é o caso do inciso $\mathrm{V}$, que a prevê para "reorganizar as finanças da unidade da Federação que: a) suspender o pagamento da dívida fundada por mais de dois anos consecutivos, salvo motivo de força maior; e b) deixar de entregar aos Municípios receitas tributárias fixadas nesta Constituição, dentro dos prazos estabelecidos em lei". E também para assegurar a "prestação de contas da administração pública, direta e indireta" (art. 34, VII, d) e a "aplicação do mínimo exigido da receita resultante de impostos estaduais, compreendida a proveniente de transferências, na manutenção e desenvolvimento do ensino e nas ações e serviços públicos de saúde" (art. 34, VII, e).

Embora não tenham sido essas as razões que justificaram essa intervenção, é bom lembrar que o Ministério Público Federal já representou ao Supremo Tribunal Federal para que houvesse intervenção federal no estado do Rio de Janeiro, com base no já citado artigo 34, VII, $d$, tendo como fundamento o enorme prejuízo aos trabalhos do Tribunal de Contas do Estado após o afastamento, por ordem judicial, de seis dos sete conselheiros que o compunham. ${ }^{3}$

Ainda que a intervenção em vigor não tenha sido formalmente motivada por razōes financeiras, o comprometimento das finanças públicas fluminenses é uma das principais - se não a principal - razão que está deixando o Rio de Janeiro um caos. Desse modo, as questóes financeiras que envolvem a intervenção federal ora em vigor são extremamente importantes e interessantes sob o ponto de vista jurídico e econômico. E considerando o "pioneirismo" da medida, são novas, sem precedentes e de difícil solução. E precisam ser resolvidas, com rapidez, dada a óbvia urgência a que estão submetidas.

Um socorro da União a estados ou municípios invariavelmente envolve a aplicação de dinheiro púbico, o que traz à tona discussões complexas envolvendo a partilha de recursos em uma Federação. O próprio decreto de intervenção permite prever esse aporte financeiro, como se vê do seu artigo $3^{\circ}, \S 3^{\circ}$ : "O Interventor poderá requisitar a quaisquer órgãos, civis e militares, da administração pública

Rodrigo Janot Monteiro de Barros, procurador-geral da República, em 26 de abril de 2017 (Ofício 97.442/2017-AsJConst/SAJ/PGR). Vide notícia no ConJur: Rodrigo Janot pede intervenção federal no Rio de Janeiro por crise no TCE-RJ, publicada em 29 de abril de 2017. 
federal, os meios necessários para a consecução do objetivo da intervenção" (grifei). E, se a situação do Rio de Janeiro está em forte crise, é previsível e fácil de presumir não haver recursos financeiros próprios suficientes para restabelecer a ordem na administração da segurança pública, tornando evidente "que sem o aporte significativo de recursos federais a intervenção federal não conseguirá minimamente atingir seus objetivos", como bem observou a deputada Laura Carneiro. ${ }^{4}$

Muitas questões podem ser colocadas: é justo que contribuintes do país todo paguem a conta de determinado estado da federação, quando o motivo que levou à necessidade de socorro não adveio de qualquer fato imprevisto, mas provavelmente em decorrência de má gestão e corrupção? Por outro lado, é razoável fazer a população local sofrer as consequências desses fatos, de modo muitas vezes desumano, com paralisação de serviços essenciais na saúde, educação, ou, como no caso presente, falência do sistema de segurança pública, deixando que prevaleça a desordem, o caos social e um ordenamento jurídico inoperante? Com o estado deixando de exercer o controle da sociedade, que passa a ser "terceirizado" para o crime organizado, por meio de facçôes criminosas, traficantes e milicianos?

Essas são apenas algumas das questôes de fundo que indicam quão complexa é a intervenção da União nos estados e seus reflexos financeiros.

Outras mais específicas, de natureza eminentemente financeira - e, portanto, fundamentais para o sucesso da ação -, também não ficam claras.

O decreto que instituiu a intervenção (Decreto Federal 9.288, de 16 de fevereiro de 2018) atribui ao interventor, que é um agente federal subordinado ao presidente da República, o poder de "requisitar se necessário, os recursos financeiros, tecnológicos, estruturais e humanos do Estado do Rio de Janeiro afetos ao objeto e necessários à consecução dos objetivos da intervenção" (art. 3o, $\$ 2^{\circ}$ - grifei).

É uma medida curiosa, pois não deixa claros os limites desse poder. Permite que sejam requisitados todos os recursos necessários? Limitados ou não pelas dotações específicas já previstas para o setor? Obriga a concessão de créditos adicionais, se necessário? E se os recursos exigidos pela intervenção provocarem excessos de gastos vedados pela legislação, como, por exemplo, eventuais ultrapassagens das metas fiscais previstas?

Poderá haver contingenciamento nas dotações para a segurança pública? Quem será responsabilizado em caso de descumprimento de limites constitucionais e legais? O interventor? Será ele o ordenador de despesas?

4 Relatório que integra a Mensagem ao Congresso Nacional 80, de 2018, da deputada federal Laura Carneiro. 
A gestão dos recursos depende, muitas vezes, de atos de outros órgãos, que coordenam a administração financeira do ente federado, como é o caso da Secretaria de Estado de Planejamento e Gestão, que não está abrangida pelo decreto de intervenção. Um potencial conflito entre o interventor e demais órgãos da administração pública fluminense que pode dar origem a obstáculos ao fiel cumprimento das obrigações.

O próprio sistema de fiscalização financeira institucionalmente organizado pode gerar insegurança jurídica, uma vez que teremos órgão estaduais e respectivos recursos sendo geridos por agentes federais, além dos eventuais recursos federais que serão adicionados para que os órgãos estaduais possam cumprir suas funçôes. ${ }^{5}$ Uma possibilidade de gerar duplicidade de controles, ou, o que seria até pior, nenhum controle.

A participação da União com aportes financeiros já chamou a atenção do TCU, que instaurou processo de acompanhamento ${ }^{6}$ voltado a acompanhar as despesas da União e atos administrativos praticados no âmbito da intervenção federal, ${ }^{7}$ uma prudente medida para fiscalizar a aplicação dos referidos recursos, especialmente em razão da urgência e rapidez com a qual devem ser desembolsados, o que exige cuidado redobrado para evitar desvios e desperdícios.

A regra é submeter ao sistema de fiscalização próprio do titular dos recursos, ${ }^{8}$ o que evidentemente deixará os setores envolvidos na intervenção submetidos ao controle do TCE-RJ e do TCU; mas a linha demarcatória da atuação de cada um certamente será tênue, muito conflitos surgirão, e os responsáveis e envolvidos na intervenção, além dos óbvios problemas que enfrentarão com relação aos limites de sua atuação sob o ponto de vista das questôes de segurança pública, ainda terão de

5 Imagine-se, por exemplo, mais de um órgão de controle se manifestando de forma divergente sobre a legalidade ou não das despesas públicas feitas pelo órgão sob intervenção.

6 O procedimento de acompanhamento está previsto no artigo 241 do atual Regimento Interno do TCU: "Acompanhamento é o instrumento de fiscalização utilizado pelo Tribunal para: I - examinar, ao longo de um período predeterminado, a legalidade e a legitimidade dos atos de gestão dos responsáveis sujeitos a sua jurisdição, quanto ao aspecto contábil, financeiro, orçamentário e patrimonial; e II - avaliar, ao longo de um período predeterminado, o desempenho dos órgãos e entidades jurisdicionadas, assim como dos sistemas, programas, projetos e atividades governamentais, quanto aos aspectos de economicidade, eficiência e eficácia dos atos praticados".

7 "TCU vai fiscalizar contas da intervenção no Rio" (Folha/Uol, 21 de fevereiro de 2018).

8 "A competência da TCU é fixada a partir da origem dos recursos públicos, logo independe da natureza do ente envolvido na relação jurídica, inclusive na seara do Sistema Único de Saúde" (STF, RE 934.233 AgR, relator(a): min. Edson Fachin, j. 14.10.2016). 
enfrentar também insegurança jurídica em razão da gestão compartilhada dos recursos envolvidos.

É de se imaginar igualmente que os entes federativos envolvidos possam suportar encargos financeiros excepcionais decorrentes de ações indenizatórias motivadas por eventuais excessos cometidos durante as operações militares, como já antevisto no caso do dito "fichamento" dos moradores de comunidades pobres.? Também aqui, a falta de clareza quanto às competências da União e do estado do Rio de Janeiro pode gerar dúvidas quanto ao responsável pelas reparações, gerando reflexos no dimensionamento dos riscos fiscais e passivos contingentes de cada entidade. $^{10}$

Mais uma vez se vê que a falta de planejamento e irresponsabilidade fiscal comprometem gravemente o funcionamento de um ente da federação e a população é chamada a pagar a conta. Financeira e não financeira. E a "administração-bombeiro" volta a agir, para apagar mais um incêndio, desta vez de grandes proporções. A falta de seriedade na aplicação das normas de Direito Financeiro continua a produzir vítimas inocentes.

9 "Especialistas criticam 'fichamento' de moradores durante operação em favelas" (O Globo, 23 de fevereiro de 2018).

10 De maneira simplificada, pode-se dizer que os riscos fiscais, que devem ser previstos periodicamente em anexo próprio da Lei de Diretrizes Orçamentários, são eventos que venham a impactar negativamente as contas públicas. Os passivos contingentes são riscos relacionados a obrigações futuras que escapam ao controle da entidade ou obrigações presentes não reconhecidas, de liquidação incerta ou de valor não mensurável. 
